\title{
The peripheral serotonin, the serum osteocalcin and CrossLaps: the assay in menopausal women
}

Authors M.Carsote, C.Capatina, A.Caragheorgheopol, D.Peretianu, D.Manda, R.Baloescu, AM.Stefanescu, D.Paun, C.Poiana

Hospital "C.Davila" University of Medicine and Pharmacy; "C.I.Parhon" National Institute of Endocrinology, Bucharest, Romania "SCM Povernei" Medical Centre, Bucharest, Romania

\section{Objectives:}

The skeleton health is reflected by the turnover markers as serum CrossLaps ( $C L=$ bone resorption), and serum osteocalcin ( $\mathrm{OC}=$ bone formation), and by the calcium metabolism parameters (as ionic blood calcium, and, probably, by the 24 -hour urinary calcium $=24-\mathrm{h} \mathrm{ca}$ ).

The peripheral serotonin might have intra-normal levels in patients with osteoporosis but yet represents a part of the complex equation related to the bone homeostasis.

Aim: we analysed the bone parameters, including serotonin in relationship to the bone loss as reflected by central DXA.
This is a transversal study in menopausal women, starting from 2009 up to the present.

No patient with active neoplasia or with tumours history (including primary hyperparathyroidism) was included.

The patients with osteoporosis or anti-resorptive therapy for osteoporosis were also excluded.

The lumbar DXA (Prodigy) provided the bone mineral density (BMD), and the WHO criteria allowed the including the patients into the osteopenia or the normal group.

The blood assay were ionic calcium, OC, CL (ELISA kit), serotonin (ELISA), parathormon (PTH), 25-hydroxy vitamin D or 25OHD, (chemiluminescence), the urinary assay was 24-h ca.

Statistical significance (SS) was considered at $p<0.05$.

\section{Results:}

55 women had osteopenia $(\mathrm{N} 1=22)$, and normal DXA (N2=33).

The ionic calcium was not SS different between the 2 groups ( $4.02 \mathrm{vs} .3 .92 \mathrm{mg} / \mathrm{dL}, \mathrm{p}=0.23$ ), neither PTH (42.6 vs. $44.6 \mathrm{pg} / \mathrm{mL}, \mathrm{p}=0.5)$, serotonin $(155.36$ gs. $166.9 \mathrm{ng} / \mathrm{mL}$, normal<440ng $/ \mathrm{mL}, p=0.55)$, 24-ur ca ( 0.14 vs. $0.18 \mathrm{ng} / \mathrm{mL}, p=0.19), 250 \mathrm{HD}$ (14.64 vs. $13.52 \mathrm{ng} / \mathrm{mL}, p=0.5)$. BC, and $O C$ are SS higher in osteopenia group versus normal: 0.49 vs. $0.38 \mathrm{ng} / \mathrm{mL}(p=0.05)$, respective 25.68 vs. $17.73 \mathrm{ng} / \mathrm{mL}(p<0.005)$.

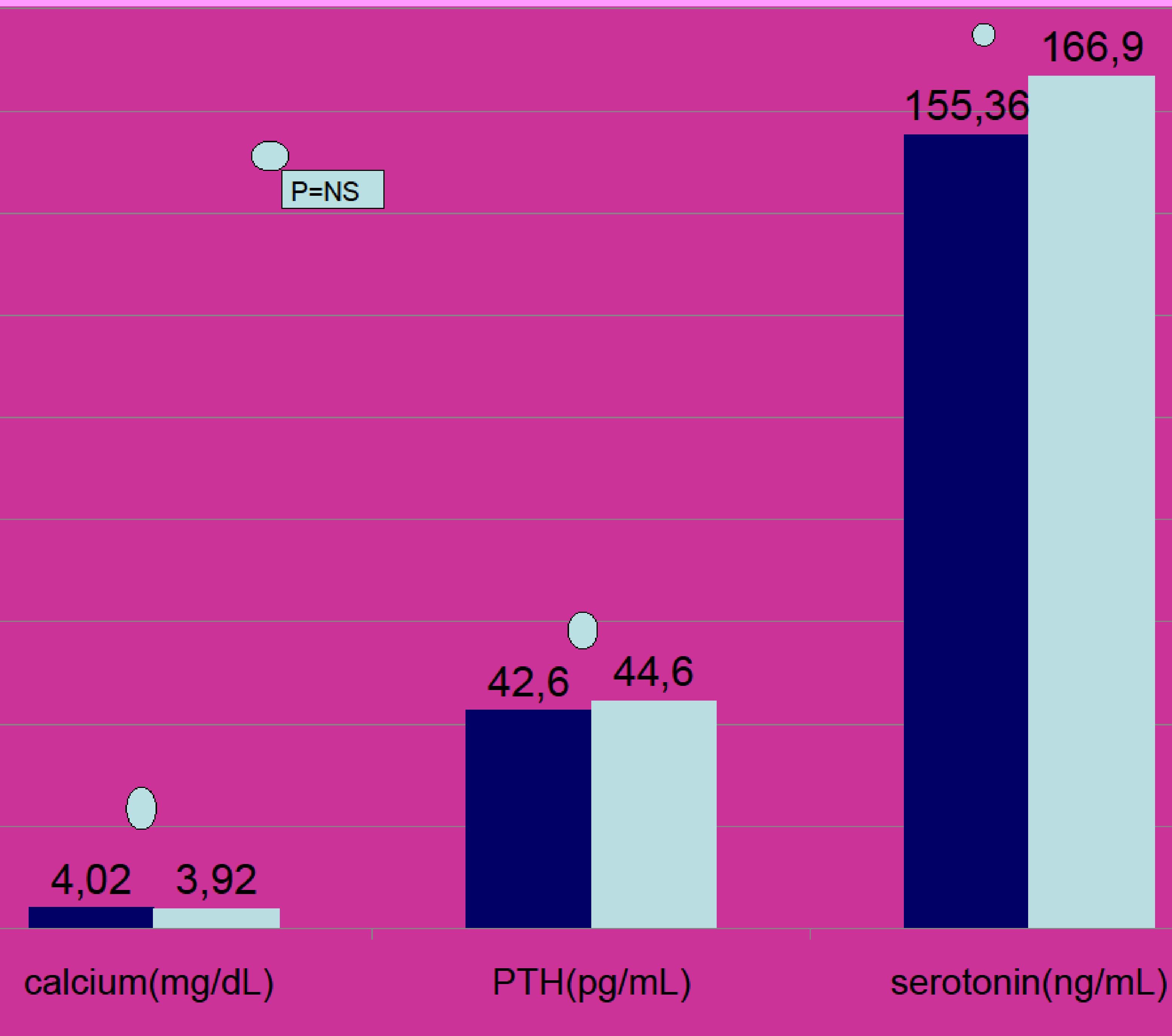

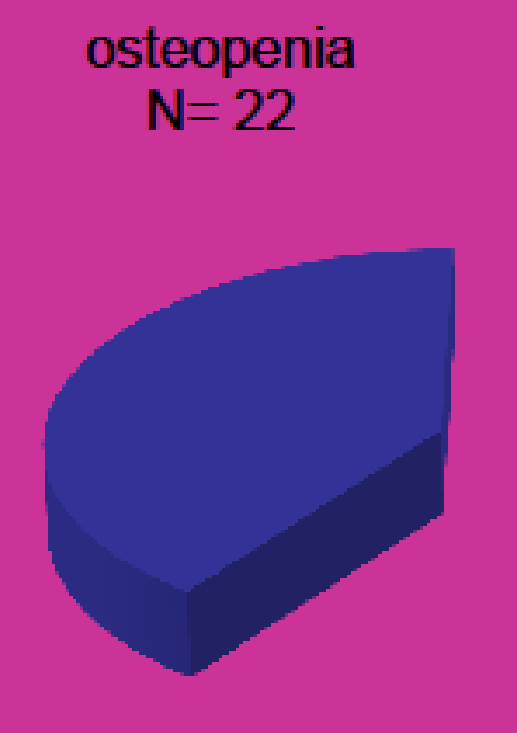

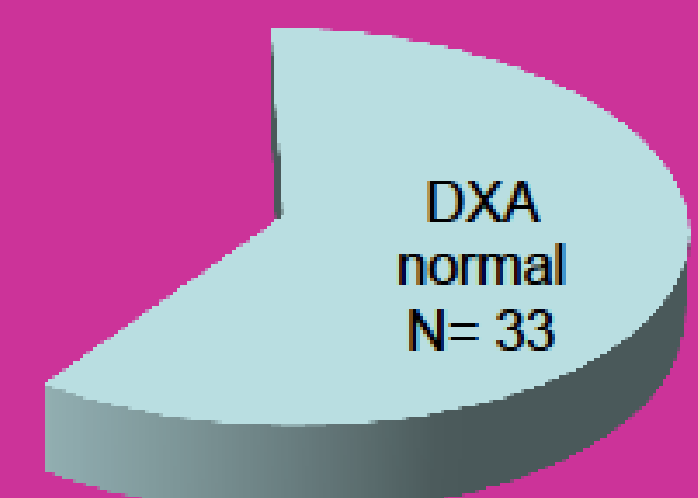

- osteopenia DXA normal

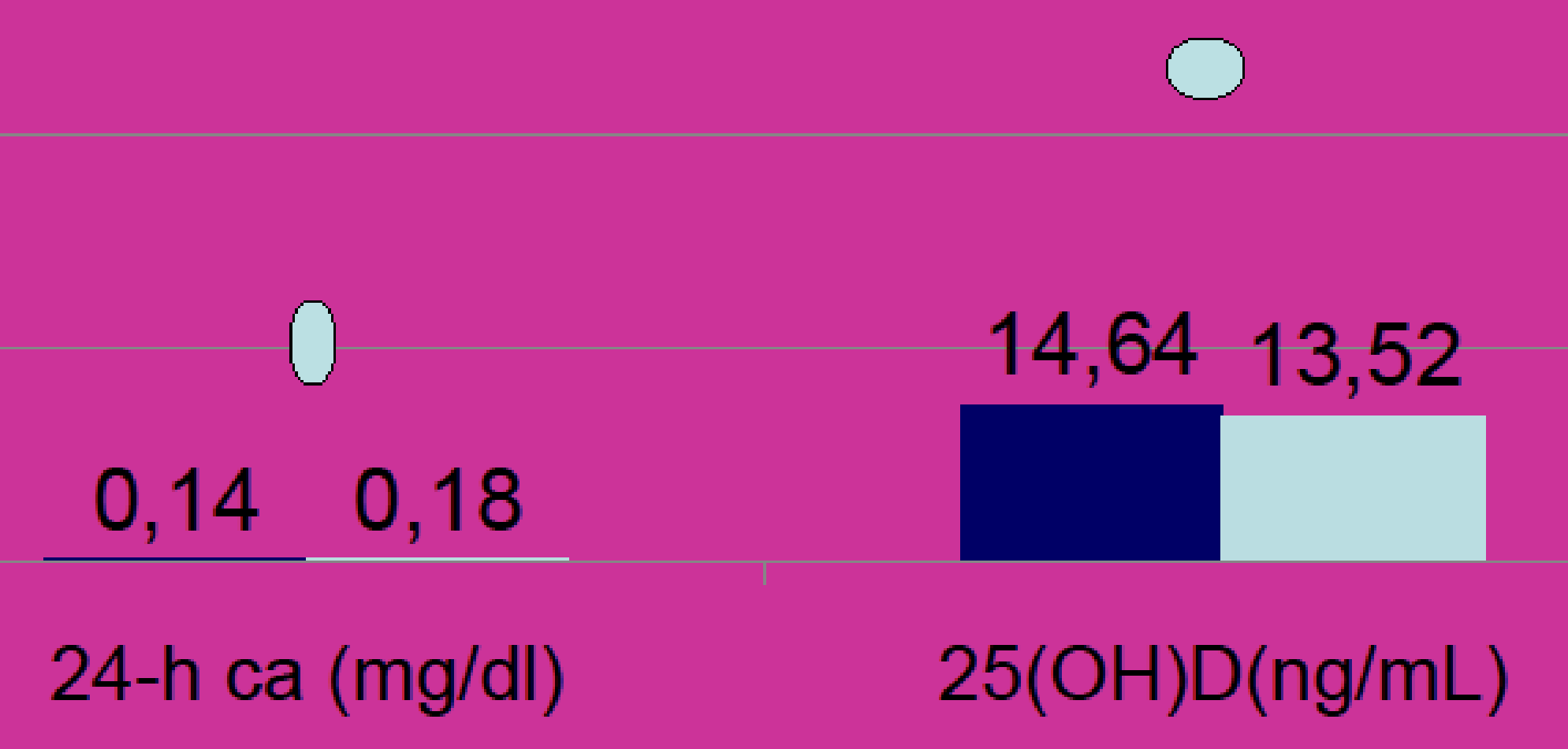

\section{Conclusions:}

Based on our observations, the bone turnover markers are higher in women with osteopenia versus normal, while the serotonin, or the calcium (regardless urinary or serum) and PTH are similar.

Overall, a high prevalence of low 25 -hydroxy vitamin D levels is found in menopause. 